characteristics. Cathodic protection is being applied to some $600 \mathrm{~km}$. of new gas mains every year. $\mathrm{Mr}$. C. W. N. McGowan described a cathodic protection installation for jetty piling in the Persian Gulf, and Mr. H. C. S. Hayes gave details of the experience of the General Post Office. Corrosion of lead-sheathed cables in earthenware ducts is widespread, and although this can be prevented by wrapping with impregnated hessian tape, this solution to the problem is not attractive owing to its expense and the space taken in the duct. Preliminary tests of cathodic protection have been successful.

A number of speakers discussed the techniques of measuring pipe/soil potentials using copper/copper sulphate reference electrodes, and the significance of the results obtained. Mr. J. H. Gosden showed how such measurements had facilitated the diagnosis of corrosion of lead-covered cables which had been caused both by stray currents from an adjacent traction system and by electrolytic action. Mr. Spencer briefly replied to the discussion.

The third session was devoted to the following papers: "Corrosion of Buried Copper and Forrous Strips in Natural and Salted Soils", by the British Electrical and Allied Industries Research Association, and "Tests on the Corrosion of Buried Alumin. ium, Copper and Lead", by P. T. Gilbert and F. C. Porter. The first paper was introduced by Dr. G. Mole and the second by Mr. Porter.

Dr. F. A. Champion considered the results in the first paper could have been better presented in the form of a simple plot of corrosion against time. He agreed that the eifect of salting, as sometimes carried out when earthing plates are installed, is largely confined to increasing corrosion in the early life. Regarding the second paper, he considered that the presence of relatively large amounts of chloride and sulphate is not in itself an adequate explanation of the corrosion of aluminium, and suggested that mol' $\theta$ attention should be paid to the question of the copper content of the soil waters. He referred briefly to the results of some tests carried out by his colleagues, which showed that a protective scheme incorporating barium chromate as inhibitor gave promising results on aluminium specimens buried for two years in cinders.

Mr. Gosden drew the general conclusion that bare copper is normally adequately resistant to soil corrosion, that aluminium should not be buried without a good protective coating and that the position of lead is intermediate. He gave details of the experience of the British Electricity Authority with 130,000 miles of lead-sheathed cable. In 1949, 106 faults occurred, of which sixty-three were due to electrolytic action and twenty-seven to chemical action of various types. Mr. J. B. Cotton mentioned the danger of accelerated attack at defects in a tin coating on copper.

Mr. E. A. G. Liddiard thought clad aluminium ulloys have possibilities. In reply to his query about experiments to follow corrosion by change in electrical resistance, Dr. Hudson said that plans for such experiments had been well advanced but circumstances had necessitated their abandonment. $\mathrm{Mr}$. R. L. Davies described some experiments which suggested that aluminium could corrode rapidly in anaerobic conditions.

Dr. Mole and Dr. Gilbert replied briefly to the discussion.

The papers on which the discussion was based and a full account of the discussion will be published in due course by the Iron and Steel Institute.

\section{NATIONAL RESEARCH COUNCIL OF CANADA}

\author{
ANNUAL REPORT FOR 1950-51
}

$T$

HE thirty-fourth annual report of the National Research Council for 1950-51* includes the report of the president, Dr. C. J. Mackenzie, the Financial Statement and a financial statement and summary of the operations of Canadian Patents and Developments, Ltd., for the year ended March 31, 1951.

In the Division of Applied Biology the macromolecule laboratory is investigating the size, shape and charge of several carbohydrate extracts of marine algæ, upon which their industrial value depends, and the microbial decomposition of cellulose is also being studied with the view of the utilization of industrial wastes. In the plant science section the mechanism of photosynthesis and particularly the transformation of absorbed light energy into chemical energy or reducing power is being investigated, while the industrial fermentations group has found that Pseudomonas hydrophila is superior to all other organisms for the production of $2: 3$-butylene glycol from sulphite waste liquor or from beet molasses. Re-designing the overhead bunkers in the standard railway refrigerator-car by extending the cooling surface with fins and improving the air circulation has resulted in a reduction of the air temperature in the car by $4.5^{\circ} \mathrm{F}$.

Work on marine products has been concluded, and the project will be transferred to the Maritime Regional Laboratory. Conditions for extracting alginates from Canadian seaweeds were established, and soluble chitosans obtained by deacetylating chitin from lobster shells. In the Prairie Regional Laboratory, Saskatoon, work was continued on the fermentation of sugars by the corn-smut fungus, Ustilago zece, and studies were continued on the production of glycerol with Bacillus subtilis to establish the conditions giving rapid fermentation with consistently high yields from a starch substrate. The possibility of using mould enzymes for solubilizing or modifying materials which contain protein is being studied as well as the formation of lignin in wheat plants, and work was continued on spray-drying wheat gluten.

In the Division of Chemistry a specially designed ultrasonic interferometer has been used to measure the velocity and absorption of sound in the region of the liquid-gas critical temperature. While the photoconductivity of anthracene was confirmed, no photoconductivity was observed for octadecane. More information has been obtained on the shape factor of the individual particles and agglomerates in thixotropic suspensions from the rheological properties of the systems as a whole. Elucidation of the structure of the lupin alkaloid thermopsine has supplied the key to the structure of two new alkaloids, $\alpha$-isosparteine and $\alpha$-isolupanine, while progress is reported in the interpretation of infra-red spectra of fatty acids. In applied chemistry the pilot-plant work on the recovery of oil from Alberta bituminous sands has continued, and a combination of water separation with flash distillation in a fluidized bed appears likely to provide an economic process for the recovery of oil from such sands. Besides investigations on the causes of normal corrosion in domestic hot-water heaters and the cooling-systems of internal com-

* Thirty-fourth Annual Report of the National Research Council of Canada, 1950-51. (N.R.C. No. 2463.) Pp. 43. (Ottawa: King's Printer, 1951.) 
bustion engines, fundamental work has been carried out on the mechanism of corrosion inhibition and the rate of oxidation of heat-resistant alloys at high temperatures. Identification of the constituents of Canadian marine and vegetable oils was being continued in part with the view of alternative sources of drying-oils, and laboratory work on a new silver catalyst for the production of ethylene oxide was nearing completion.

In the Division of Physics a Collins liquid-helium cryostat has been installed, while the acoustics group has done much to supply the operational maintenance of the improved marine fog-horn already developed. Using the photographic emulsion technique, a study of very high-energy nuclear disintegrations caused by incoming primary cosmic-ray particles has provided evidence that both neutral and charged mesons are produced in the interaction between such incoming particles and the elementary nucleons (neutrons and protons) which make up atomic nuclei. Using the counter technique an accurate comparison has been made of the intensities of cosmic rays continuously recorded at Ottawa and at Resolute. In the radiology laboratory trial sources of radioactive cobalt have been investigated to obtain information required for the design of radiation therapy equipment using very large radioactive sources, and a method has been developed for measuring the energy output and obtaining the isodose curves of beta-ray plaques used in some types of cancer therapy. Experimental work on the determination of the acceleration due to gravity by direct observation on a falling body continued in the metrology laboratory. The optics laboratory developed a new method, using the Herschel effect, for increasing the effective range of photographic papers, while the spectroscopy group analysed the infra-red spectra of nitrous oxide and heavy methylacetylene and elucidated their molecular structure. In theoretical physics, a systematic study was made of the quantization of the classical theory of charged particles with spin, and the validity of the usual perturbation theory in the auto-ionization of light atoms was studied; calculations of the probabilities of excitation of vibrational states of hydrogen by electrons, protons and hydrogen atoms were made and theories developed for the ferro-electric effect of certain crystals and the dissociation of oxygen molecules in the upper atmosphere.

Housing has continued to dominate the selection of projects for investigation by the Division of Building Research; but jointly with the Division of Chemistry an extensive programme of corrosion research is in operation as well as one on paint failures, and a detailed survey of fire research needs in Canada and of fire research and testing facilities in North America was approaching completion. In the Division of Mechanical Engineering, wind-tunnel studies have been made on four Canadian aircraft, while the work of the model-testing basin was expanded and included tests of naval vessels. Factors affecting ice formation on large bodies of water were studied in connexion with the possibility of maintaining ice-free navigation channels in winter, os well as ice crystal formation in fuels and the operational behaviour of low-temperature lubricants.

The programme of the Radio and Electrical Engineering Division comprised about thirty projects in electrical engineering, electronics, radar and radiophysics. A new marine radar with the minimum range of only ten yards was developed, which gave excellent performance, especially in small harbours, in passing ships at close quarters and in docking; and other developments included a microwave shore beacon for use with a simple inexpensive microwave receiver on board ship, a radio-frequency mass spectrometer which employs no magnetic field, an experimental electron accelerator as a source of betaor gamma-rays with an energy of four million volts, and a new surge generator and a $400-\mathrm{kW}$. pulsegenerator providing extremely bright flashes of light, lasting a few microseconds, at 5-500 times a second. A theoretical study of servo-mechanism performance based on a generalized frequency-response analysis was completed and the infra-red detector used to locate faulty joints on power-transmission lines redesigned. In the Atomic Energy Project, using the electron-pair, neutron and beta-ray spectrometers, new energy-levels have been found in the nuclei of several atoms, and the structure of certain compounds, such as deuterized ammonium chloride and carbon tetrachloride, has been determined. With the new high noutron flux available in the field, new isotopes have been obtained by successive capture of neutrons.

\section{SUMMER DAY-TIME METEOR STREAMS OF 1949 AND 1950}

TNDER the general heading of "The Summer Daytime Meteor Streams of 1949 and 1950", three papers, each dealing with a different aspect of these daylight meteor streams, have recently been published*. The first paper, by A. Aspinall and G. S. Hawkins, describes the method of measurement of the radiant positions and activity. The original single-directional aerial, movable in azimuth, was unsuitable for a general survey of meteor radiants, and a new apparatus has been designed consisting essentially of two fixed, narrow-beamed aerials directed along azimuths $242^{\circ}$ and $292^{\circ} \mathrm{E}$. of $\mathrm{N}$., operating on a wave-length of $4 \mathrm{~m}$. As the radiant of an active shower moves across the sky, it produces echoes in each aerial in turn, and these echoes are recorded by continuous photography; from their range-time variation the right ascension and declination of a major shower can be determined to within $+1 \cdot 5^{\circ}$. Table 2 of this paper gives a comparison of the radiants of four streams from 1947 to 1950 ; these include the $\eta$-Aquarids-the well-known stream established by visual methods and which is supposed to be associated with the debris of Halley's Cometand also the $\beta$-Taurids, the $\zeta$-Perseids and the Arietids. The last two occur simultaneously and wero not successfully interpreted with the single aerial; but the streams have been definitely separated with the new apparatus. In addition to these permanent streams, there are several others which are very active but are of a transient or long-period character, and there are numerous meteors which the apparatus in use fails to assign to any definite radiants.

The second paper, "Measurement of the Velocities", by J. G. Davies and J. S. Greenhow, explains how the radio-echo diffraction technique is used to determine meteor velocities. A description of this apparatus appeared in Nature, 161, 596 (1948), and 8 short account of the method used is given in the papor. Tables 1 and 2 contain the lists of velocities obtained in 1950 and 1949 respectively, and other relevant information. The velocity distribution for

* Mon. Not. Roy. Astro. Soc., 111, No. 1 (1951), communicated by * Mon. Not. Roy. Astro. Soc., 111, No. 1 (1951), communicated by
Prof. A. C. B. Lovell, Jodrell Bank Experimental Station, University Prof. A. C. B. 